University of Northern lowa

UNI ScholarWorks

Graduate Research Papers

Student Work

2017

\title{
Technology and young children
}

Jamie Vircks

University of Northern lowa

Let us know how access to this document benefits you

Copyright (C2017 Jamie Vircks

Follow this and additional works at: https://scholarworks.uni.edu/grp

Part of the Curriculum and Instruction Commons, and the Early Childhood Education Commons

\section{Recommended Citation}

Vircks, Jamie, "Technology and young children" (2017). Graduate Research Papers. 241.

https://scholarworks.uni.edu/grp/241

This Open Access Graduate Research Paper is brought to you for free and open access by the Student Work at UNI ScholarWorks. It has been accepted for inclusion in Graduate Research Papers by an authorized administrator of UNI ScholarWorks. For more information, please contact scholarworks@uni.edu. 


\title{
Technology and young children
}

\begin{abstract}
This review examined the purpose of technology use with young children. Examination of literature on effects of technology usage in the classroom, and ebook use to teach emergent literacy skills, was done. Insights showed that young children are learning more than just academic skills while using technology. They are learning cultural and social norms. In the classroom, children as young as three years old are being introduced to technology as a way to teach practice and reinforce new literacy skills. The review had mixed results as to whether technology use with young children to teach literacy skills is effective. Further insights were synthesized and recommendations were made for the use of technology with young children.
\end{abstract}


Technology and Young Children

\author{
A Graduate Research Paper \\ Submitted to the \\ Division of Early Childhood Education \\ Department of Curriculum and Instruction \\ In Partial Fulfillment \\ Of the Requirements for the Degree \\ Master of Arts in Education \\ UNIVERSITY OF NORTHERN IOWA
}

By

Jamie Vircks

September 2017 
This Research Paper by: Jamie Vircks

Titled: Technology and Young Children

has been approved as meeting the research requirement for the Degree of Master of Arts in Early Childhood Education.
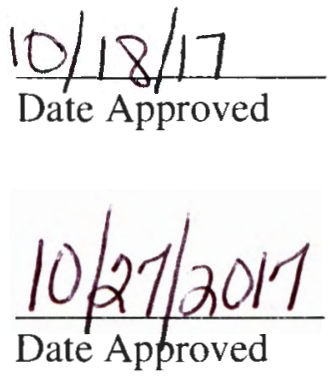

$11 / 1 / 2017$

Date Approved

\section{Allison Pattee}

\section{Graduate Faculty Reader \\ Gloria Kirkland Holmes}

'Graduate Faculty/Reader

Deborah Tidwell

Head, Department of Curriculum and Instruction 
ABSTRAC'T

This review examined the purpose of technology use with young children. Examination of literature on affects of technology usage in the classroom and the ebook use to teach emergent literacy skills was done. Insights showed that young children are learning more than just academic skills while using technology. They are learning cultural and social norms. In the classroom, children as young as three years old are being introduced to technology as a way to teach practice and reinforce new literacy skills. The review had mixed results as to whether technology use with young children to teach literacy skills is effective. Further insights were synthesized and recommendations were made for the use of technology with young children. 


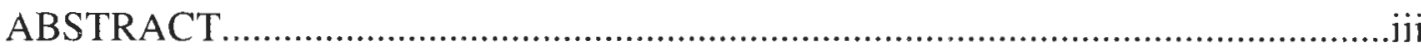

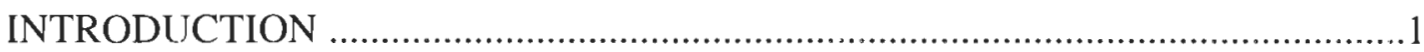

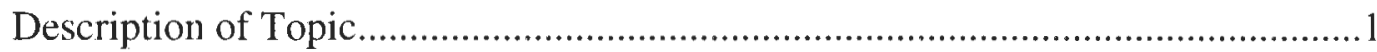

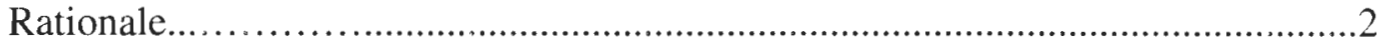

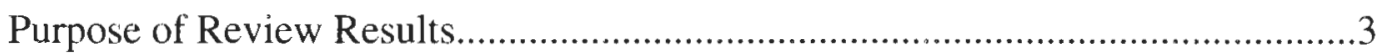

Terminology

Research Questions to Be Answered..................................................................

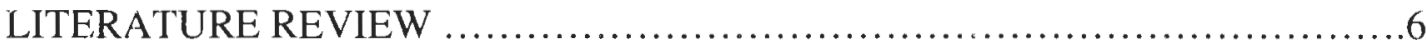

Technology use with Young Children......................................6

What Affects the Use of Technology in The Classroom? .........................10

Ebook Use to Teach Emergent Literacy Skills................................13

Ebooks have Positive Effects on Early Literacy Skills......................13

Same Outcomes in Paper Copy and Ebook......................................................16

Ebooks Are Not Good for Emergent Literacy Skills......................................20

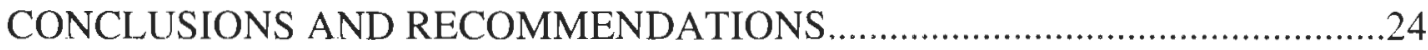

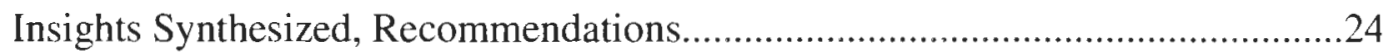

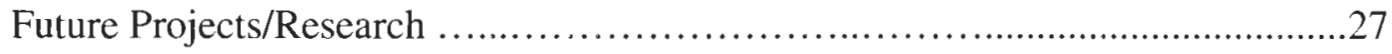

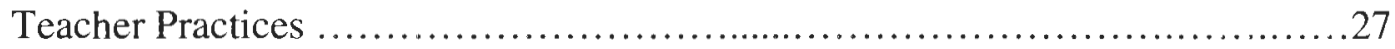

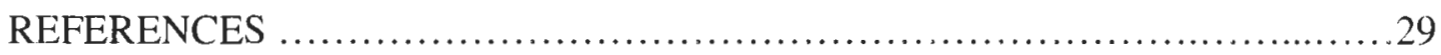




\section{Chapter I}

\section{Introduction}

With the rapid growth and expansion of digital technology, the access to technological devices and the everyday use is becoming a norm in today's culture by adults and children. Children are being exposed to technology in their homes, community and classroom. Children are using devices such as tablets and computers to engage in leisure and educational activities. Beyond academic skills, such as literacy and math, children learn cultural norms about the use of technology while observing others interactions with technology (Plowman, Stevenson, Stephen \& McPake, 2012). This study will address how young children are using technology to communicate with family members through pictures and other digital media, sornetimes even before they know how to read or write.

In classrooms, students as young as three years old are being exposed to technology for a variety of reasons. Teachers are using technology in multiple ways, including supplementing the curriculum and teaching students with different approaches. Teachers are using technology such as ebooks, iPads, and computers to assist in delivering instruction on letter sounds, story comprehension, phonological awareness, word reading and other early literacy skills needed to be successful in today's society. While reviewing articles focused on technology use, I found mixed results showing positive and negative outcomes for children while using technology to teach literacy skills. Featured in these reviews are ideas that help determine why and how teachers use technology in their classrooms.

\section{Description of Topic}

In this chapter, I will describe technology use with young children in the context of their use 
at home and at school. I will also discuss the impact ebooks can have on their literacy skill acquisition. Following this I will discuss how the results of this review will help contribute to the use of technology with young children. I continue by defining some important terms that appear in this paper. Finally, the three research questions that guide this paper will be stated and addressed.

\section{Rationale}

Children are using technology more extensively in the classroom. In the past six years that I have been teaching preschool, I have gone from having a dated computer that only on occasions worked, to having a projector mounted with an apple TV, and three classroom iPads purchased for me to use with my students. This is just one example of how technology use is becoming more and more used in classrooms today. Even children as young as preschool are independently using technology to learn and play. Due to the increase in technology use by young children, The National Association for the Education of Young Children (NAEYC) and the Fred Rogers Institute gave guidelines on technology use with young children. In this position statement their recommendations were:

that child care settings limit screen time (including television, videos, digital media, video games, mobile media, cell phones, and the Internet) for preschoolers (age 2 through 5) to fewer than 30 minutes per day for children in half-day programs or less than one hour per day for those in full-day programs. The report further encourages professionals to work with parents to limit screen time to fewer than two hours per day for children age 2 through 5 (2012, p. 3$)$.

The awareness and understanding that schools are using technology in the classroom 
encouraged this research and provided insight into making the best decisions on how to use technology with young students. Gaining more information on specific applications to use in classrooms or how iPads could impact students learning were key items I hoped to collect data on for future implementation. A focus on Literacy outcomes helped narrow and focus my search. Literacy and math are two domains of learning that educators address in early childhood.

While doing a search of topics I began finding a lot of articles dealing with the use of ebooks and young children. Although ebooks can be used on computers or iPads, a good amount of articles running experiments with the effects of using them with young children and the children's literacy gains were found.

\section{Purpose of Review Results}

The results of my review will be benefit teachers and parents. Those adults who interact with children frequently will understand how technology plays an important role in a child's life. Parents will see that even when their child is not directly using technology, there is still an impact and children are learning from each witnessed interaction or involvement. Teachers benefit from reviewing reasons for using technology in their classrooms. Teachers can discuss with administration and school officials regarding barriers to using technology in the classroom and help make a plan to overcome these issues. The results regarding ebook use may provide insight on how ebooks are most effective in the classroom setting.

\section{Terminology}

For the purpose of this review of literature, the below terms will be defined as shown below.

ebooks- This is a term used as an abbreviation for electronic books. These books may be in 
different formats and accessed on computers or tablets. In general these books are digital copies that have the ability to read the words to the person using the application. There are interactive pieces to the stories, such as clicking pictures to activate animation, or clicking a word to provide a definition.

Emergent Literacy Skills- This is an umbrella term that encompasses many different skills needed to learn to read and write later in life. This paper uses this term to identify skills such as:

Phoneme- the smallest unit of sound in a word, for example $/ \mathrm{k} /$ in the word cat.

Phonological Awareness- the ability to put together and pull apart units of sound in words.

Print Concepts- understanding the written language. Some examples of this might be being able to determine the difference between a letter, word, and sentence, spaces, punctuation, and what direction to read (left to right).

Reading Comprehension- being able to understand and interpret what you have just read.

Socioeconomic Status (SES)- an identifier to compare people's social and economic worth. This calculation is based off of a combination of a person's income, education level and occupation. This term can also be identified as social status or class.

\section{Research Questions to Be Answered}

To better understand the uses of technology with young children and its potential academic benefits, I considered these three questions:

1. How are young children using technology? 
2. What affects teachers' decisions to use Technology with young children?

3. Are ebooks an effective tool for teaching young children emergent literacy skills? 


\section{Chapter II}

\section{Literature Review}

The articles reviewed in this paper will discuss how technology is being used with young children to help teach emergent literacy skills. The following chapter will answer these research questions:

1. How is technology being used by young children?

2. What effects teachers' decisions to use Technology with young children?

3. Are ebooks an effective tool for teaching young children emergent literacy skills? This review will be beneficial to educators, especially those who work with younger children (ages three to six) as they determine the level of technology used in their classrooms.

\section{Technology use with Young Children}

Technology is used by children in different settings for different reasons. The following will examine how children are exposed to technology, and its use in the home and at school. When discussing how children use technology at school. teachers' thoughts and perception of technology will be addressed.

Technology is being used with children starting at very young ages. Even before children are able to manipulate and independently use technology, they are being exposed to technology when adults or older children use devices such as the television (TV), radio, or cameras. Plowman, Stevenson, Stephen, \& McPake (2012) examined how children used technology in their home. Children in this study were three years old when the study began. Young children are exposed to various learning opportunities in their home before attending formal schooling. Although Plowman et al. (2012) focused on overall technology use in the home, the article 
articulated how young children use technology in general when at home. The case studies for this research were done in central Scotland and focused on 14 families. The participants were 14 children, seven boys and seven girls. Seven of the families were assessed by the researchers as low socioeconomic status (SES). Plowman et al. (2012) observed "which technologies children encountered at home, how family practices influence children's encounters with technology and what children are learning through their interactions with technology" (p.30). The study began in June 2008 and continued until October 2008. Each family had multiple times that data was collected with a minimum of nine rounds per family. The researchers found that the primary form of exposure that children had to technology in the home was TV use and game consoles. Children were also exposed to the use of cameras and cameras on phones as a way of communicating with family. Computers and cellphones were not used as much with this age of children as it was noted that they still needed assistance to start activities such as "sending text messages, playing games, or viewing photographs" (Plowman et al., 2012, p.33). When looking at how the family practices influenced the children's use of technology, the researchers found that the families' chosen activities were more influential on the variations in exposures to the specific technologies, not the availability to the technology itself. This research did not draw specific conclusions to what skills that these children were learning, but did cite other work that defined some skills that could be learned by using technology. In their study, the main conclusion was that children were learning cultural norms such as how and when the children's families use technology and operational skills such as how to use the specific devices.

Espinosa, Laffey, Whittaker and Sheng (2006) observed how technology was used by young children in their homes. The researchers sought to understand if technology use varied based on the family's socioeconomic status (SES), and the impact of technology on the child's 
academic life later in school. This longitudinal study started in the 1998-1999 school year and followed the children until their third-grade year. There were 23 Kindergarteners in each of the 944 schools nationwide that were selected in the first sample year. The next year the study included first graders who did not attend kindergarten. The families reported their technology use and demographics during computer aided phone interviews. The children were assessed on their reading and math skills three times, in the spring of Kindergarten, first and third grade. The study concluded that children who came from families with higher SES had more access to technology, but also all the children, no matter their SES level, increased the level of access as the children were older. The researchers hypothesized that this could be due to the societal changes and the shift in technology becoming more common as the years progressed. The study also found that using academic computer programs at home with children in the kindergarten year had small literacy gains, whereas in the third grade there was a negative association. While doing this study the researchers were looking at multiple aspects pertaining to literacy. The study also looked at the number of books the children had in their home along with the technology. They found that "The number of children's books in the home as well as how often the child reads books are both positively related to reaching achievement" (Espinosa et al, 2006, p.430). The researchers also found that watching TV, "even Sesame Street" (Espinosa et al, 2006, p.430) showed negative literacy outcomes.

Lauricella, Barr, and Calvert (2014), evaluated how children and parents interact during traditional readings and readings from a computer storybook in their home. This study was completed with 39 children, between the ages of four and four and a half years, in their home. Only one caregiver participated during each session, even if both parents were home, only one took part in the session. The families were predominantly Caucasian and the majority of parents 
had at least a college degree. Each child was visited in their home four times by the researchers. The first session included a time where the parents were explained the study and the researchers collected demographic information. Following the initial visit there were three sessions including one day the child was read a paper copy book, one day the child was read a computer based story book, and on the last day the child was administered the Peabody Picture Vocabulary Test (PPVT). The days in which the child was read the stories were counterbalanced. The parents were not given many directions regarding how to read the books but were instructed on how to use the computer program. The researchers wanted parents to read the way they normally would with their child. The sessions were videotaped and later evaluated by the researchers. Results showed that parents were more engaged with their child when using the computer storybook format. They also found that while reading traditional books, parents were more often using word definitions while reading, compared to reading from the ebook. This study concluded that reading with children is important and useful, and both computer ebooks and paper copy books are just as beneficial for reading to children.

Young children's exposure to technology at home includes technology that works on writing and reading. Neumann (2016) investigated how the use of touch screen tablets at home for writing and reading affected young children's emergent literacy skills. This study was completed in southeast Queensland, Australia. The participants were 57 English-speaking children ranging in age from two to four years old, 29 girls and 28 boys. The researchers assessed the children's ability to name letters, sounds, numbers, as well as evaluating the participants letter writing ability, initial phoneme retrieval, and print concepts. Parents completed one questionnaire about how tablets were used in the home and literacy activities used with their child. The researchers sought to find correlations between the children's assessment and the 
home survey. The results showed that children had limited emergent literacy skills, but they did participate in many different digital and non-digital literacy activities at home (Neumann, 2016). The researcher stated that the children who played more games at home, had more print knowledge, but this relationship could not be confirmed without further research. They also were able to find a positive association between the use of literacy apps and tablet writing and typing. The use of gaming apps did not have a positive association to writing skills. One of the biggest takeaways from this article is that there needs to be more research on specific apps and longer effects regarding the use of tablets with older preschoolers.

\section{What Affects the Use of Technology in The Classroom?}

Technology integration is becoming a norm in many preschool and early childhood classrooms. With the advancement in technology, the price and accessibility is more affordable which results in more classrooms being equipped with electronics such as iPads and/or computers. Due to this, teachers need to find ways to effectively integrate this technology into their teaching in the classroom. In this section, I will discuss how teachers' beliefs about technology, along with other factors, impact the teachers' choices to use technology in their instruction.

Ihmeideh (2010) completed a study in Jordan to evaluate preschool, children ages four to six, teachers' beliefs and practices regarding computer technology use when teaching reading and writing. Questionnaires were given to 154 preschool teachers, with questions that evaluated the teachers' beliefs about the use of computers and how teachers used computers in the classroom. The questionnaire was completed using a Likert-type scale where each statement was 
rated on a one to five scale. As a follow-up to the survey, 12 teachers were interviewed to help clarify their answers. Each of these interviews were done in Arabic (the teachers native language), and lasted about 15 minutes each. The results of this study showed that Jordanian preschool teachers do not hold strong beliefs about the role of computers in the act of teaching literacy, and therefore they do not always use computers in their instructional approach (Ihmeideh, 2010, p. 74). Even with the lack of belief in using computers to teach literacy, the study reported that teachers do believe that computers are a good tool to help incorporate into the classroom. They saw value in "using computers as a part of the print-rich classroom environment, providing classroom with a computer center, providing children with developmentally appropriate literacy software, and giving children literacy activities to be done at home on a computer" (Ihmeideh, 2010, p. 74). Overall this study found that if the teachers believed that computer technology was a good way to teach literacy, they used this in their teaching, and if they did not believe in computer use, the technology use was less.

In a qualitative research study, Blackwell (2013) reviewed how iPads are used in early childhood classrooms. This researcher used 53 hours of classroom observations and teacher interviews from four different early childhood teachers, one preschool and four kindergarten teachers. Although the sample size was small, this research found that teachers used iPads integrated into their curriculum in ways that matched their own teaching philosophies. For example, some teachers were worried about the appropriateness of the use of technology with young children, and therefore did not integrate the technology into their curriculum as often as others. All the teachers did agree that iPads could engage students in ways that traditional methods might not, and could be more motivating to some students. This study also found that teachers did like the flexibility of iPads use compared to computers that have to stay in one 
locations. Teachers also liked that their young students were able to navigate on iPads easier than on computers because of their lack of motor skills. In general teachers saw the iPads as a good tool to help strengthen their learning environment for their students.

A follow up study was done in 2014 by Blackwell, Lauricella, and Wartella that expanded the number of early childhood educators that were surveyed. This time 1,234 teachers were surveyed to find out "what factors contribute to early childhood educators' technology use in the classroom?" (Blackwell et al., 2014, p.84). The researchers found that teachers need support while integrating technology into their classroom. When teachers had support in understanding how to integrate technology into their teaching, and how to help children learn with this technology, they were more likely to use technology. Blackwell et al (2014), also found two other impacts on technology use in the classroom were having a technology policy in place, and the number of years that a teacher had taught. This study also reaffirmed what the other two studies had said, the more confidence a teacher had in using technology in their classroom and the more positive their attitude toward technology use, the more likely they were to use technology with their students.

The studies in this section showed that teachers beliefs about the use of technology with young children, the amount of support they are given, and their knowledge about using technology as a teaching tool impacts the ways and amount that teachers use technology in the classroom. The researchers also suggested that teachers with more teaching experience tend to use technology more often in their classrooms. In the next section, I will review how technology such as ebooks are being used to teach emergent literacy skills such as reading comprehension to young children. 


\section{Ebook Use to Teach Emergent Literacy Skills}

Reading to children is something that many adults enjoy doing. With the advancement of technology children are starting to be "read" books in new ways. Using technology such as an iPad or computer equipped with an ebook are various new ways children are being read books. Being able to understand what you have just read or what is being read to you, is a foundational skill that is taught starting at a very young age. Without this skill, stories would not make sense and learning would become more difficult. In this section of my review I will look at articles that discuss whether or not ebooks are an appropriate way to teach ernergent literacy skills like reading comprehension to young children.

\section{Ebooks have Positive Effects on Early Literacy Skills}

Korat (2010), examined if ebooks supported kindergarten and $1^{\text {st }}$ grade student's reading comprehension. The research was conducted in Israel at schools from middle SES neighborhoods. The participants were 90 children, 40 kindergarten and 50 first graders. The control group participated in the regular school program and the intervention group read the ebook five times. Children's reading comprehension was assessed following reading the book using seven story comprehension questions. The results showed that between the two age groups, there was not a significant difference in scores. Overall the children had an $80 \%$ success rate with answering the comprehension questions. This study was also looking at students' ability to retell the story while looking at the pages of the book after being read the story, vocabulary and other early literacy skills. In general, this study found that the students showed positive gains in their early literacy skills even though they only were exposed to the ebook on five occasions.

Ihmeideh, F. M. (2014) conducted a similar study in Jordan to compare the effects of the 
use of ebooks on preschool aged (four and five-year-old) students' emergent literacy skills. The 92 student participants were selected from two different private schools and came from middle to low class families. Four classrooms in total were used, two were identified as the control group which received the regular instruction with paper copied books and the experiment group was exposed to electronic forms of books. None of the students were classified as having special needs. The study used three different books in Arabic. The books that were chosen to be used were not in ebook form before the study was conducted, so for the purpose of this study the researchers made these books into an ebook form. All participants were given a pretest, to assess their emergent literacy skills before the experiment began. Each group was exposed to the books for 15 minutes each day for eight weeks. After the eight weeks, a post test was given to each of the participants that was similar to the pre-test. The results showed that the students who were exposed to the ebook activities scored significantly higher on the posttest when evaluating the students' emergent literacy skills. This study reaftirmed the previous study that ebooks can be used as an effective tool to teach emergent literacy skills.

Rvachew, S., Rees, K., Carolan, E., and Nadig, A. (in press), conducted a study in Montreal, Canada with children from low income farnilies assessing how e-books impact the shared reading experiences between adult and child. A total of 28 children were selected from two Kindergarten classrooms. The study was conducted in three phases. Phase one consisted of a questionnaire that was sent home for parents to describe background information such as demographics, home literacy practices, and technology use. At this time children were also asked to name 12 uppercase and 12 lowercase letters. The children then were given the intervention, which included exposure to two different books. They were exposed to both the print and ebook format, one format during each week. At the end of each week a story specific test was given to 
each child measuring story retell, story comprehension and emergent literacy knowledge (Rvachew, S. et al., in press). The results from this study showed no difference in skill ability between the paper copy book and ebook when it came to children's story retell and comprehension skills. There was however an increase in adult talk about word meanings and story elements. "There were five times more mentions of print concepts when reading the ebooks than when reading the print books" (Rvachew, S. et al., in press, discussion paragraph 2). This study also found that children had significantly higher emergent literacy skill scores when reading with the ebook than the paper book. In addition, this was strongest for the children who had the lowest letter knowledge before the intervention was performed.

Shamir \& Korat (2007) examined the effects of using an ebook while working individually or as a pair. The researchers hoped to see what emergent literacy skills would benefit from using the ebook, as well as understand if working together or independently had a greater effect on the children's literacy growth. The study was done with 72 kindergarten students in low SES neighborhoods in Israel. In Israel, formal schooling starts when the child enters school at the age of six or seven, and Kindergarten is usually for children ages five to six years old. Each of the children were given a pretest to determine their abilities in the following areas before the intervention was ran; word meaning, word recognition, emergent writing, phonological awareness, and letter naming. The children then engaged with the ebook that was developed by the researchers in three different sessions, either as a pair or individually. The three sessions each had a different book mode that the children experienced, either "read only", "read with dictionary" or "read and play" (Shamir \& Korat, 2007, p. 135). The same emergent literacy tests were given after the three sessions concluded to assess the children's development of skills. The results from this study showed that all students showed improvement on their emergent 
literacy skills, both the children who worked as a pair and individually. The three areas that the children benefited from the most were word recognition, emergent writing and phonological awareness. The researchers did not identify any significant improvement in the areas of word meaning or letter naming, or between the students working alone or as a pair.

Ebooks are one form of technology that is used with young children, but other computer aided instruction can also be used to help teach early emergent literacy skills. In a study done in the UK, Mary Wild looked at how computer-aided instruction could affect phonological awareness skills with beginning readers (2009). In this study, there were 127 participants ages five to six years old that were selected from six schools in Oxfordshire. Two schools per term were worked with by the researcher two days a week for 10-12 weeks each. In each class, the students were split into three groups. Two intervention groups used a literacy program, one that was paper pencil and one that was completely on the computer. The third control group worked with the researcher, but not with the computer or on literacy skills, instead this group worked on math skills. The three groups all were given a pre-and post-test assessing their phonological awareness skills. The results from this study showed that the students in the intervention group that used the computer aided instruction made greater gains in their phonological awareness skills than the students who did the paper based instruction. It was also interesting to note that girls in the computer group made bigger gains than the boys.

\section{Same Outcomes in Paper Copy and Ebook}

The next articles will discuss findings that ebook and traditional books have the same effects on young children's early literacy skills. These studies show that although the ebooks do not have an advantage over traditional books, they also do not have a negative effect on the children's skills, therefore making the use of ebooks comparable to the use of a traditional book 
while reading with young children.

Willoughby, Evans, and Nowak (2015) examined effectiveness of using electronic ABC books compared to paper copy ABC books in Southwest, Ontario. The researchers worked with 94 children who were between the ages of three and four years old. This study assessed the children's emergent literacy skills; letter naming, letter sound, phonological awareness, and receptive vocabulary. There were three groups in this study. Children who used the alphabet books in ebook format or paper format, and then the control group were students who were only given story books and not alphabet books. After being assigned the condition, the children were put into groups of three to four children. They met with the research assistance twice a week for eight weeks for about 20 minutes each time. Each week a new book was introduced to the groups of children. The sessions started with a rhyme that related to the alphabet for the paper copy and ebook format sessions. The children in the storybook control group started with a book related rhyme. The children were read the story and given the rest of the time to look and explore that book and six other books. After the eight weeks, the children were given a post-test similar to the test given before the intervention was implemented. The results of this study showed no real impact on the children's emergent literacy skills. There was no difference between the three groups of students and their emergent literacy development. They all made gains in their skills at about the same rate. Willoughby et al. suggest that alphabet ebooks do not show an advantage over paper copy books or story books when it comes to emergent literacy development with children ages three to five years old (2015).

Vocabulary and language development while using e-books with young children is what Broemmel, Morgan and Wooten were looking at in their 2015 study. They used four different classrooms, two from a university lab school and two from a local Head Start program. There 
was one control classroom that had no ebook versions of the stories available and one test classroom which had both the paper copy and ebook copy of the stories available to students at each school. Students were given the "Peabody Picture Vocabulary T'est of Receptive Language (PPVT)" (Broemmel et al., 2015, p. 3) as a pretest and then exposed to the books based on which study group they were indentified (control or test). After five days, the students were given the same literacy test as a post test. The researchers also audio taped the child retelling the story. This was repeated for three weeks with different books each week. The results showed that both the test group and control group of students showed gains in their vocabulary usage after being exposed to the books, in either form. The researchers further suggested that these results might mean that ebooks are as useful as paper copies of books and might be able to be used as a replacement at times for teacher read-alouds (Broemmel et al., 2015). The researchers found that all students understanding of the content in the books improved after the multiple exposures to the books, in either setting. The researchers did identify a difference in the type of language the children used while retelling their stories. During the retell, the children in the lab school used more language that was similar to the book than the children in the Head Start program. This was consistent between both the control and test groups, which made the researchers wonder if this had more to do with the child's SES background than the type of books used.

A study conducted in a small town in the Netherlands by DeJong and Bus (2004), to evaluate the use of ebooks and the effectiveness compared to the use of traditional paper copy books with 18 children aged four to six years old. Children in this study were in Kindergarten and had no formal teaching of reading or writing in their schooling. The school was from an area that most of the families were Dutch and had low SES. The children were subject to three different conditions, an ebook story, a paper copy story, and a story that was not read to them at 
all which occurred during 12 different sessions throughout five weeks. Each session the children were given a pre-and post-test on story retell skills. The researchers were looking at the words that were the same as the original text, the phrases used by the students during the retell that were the same, and if the story structure was the same when the child retold the story. The results of this study illustrate that children's understanding of a story they experience independently with an ebook, are comparable to experiencing the book with an adult (De Jong \& Bus, 2004). The researchers also suggested that ebooks do meet this age of children's needs, and as long as the children have been introduced to reading previously. DeJong and Bus hypothesized that if children had not been previously read to, they might not understand how the ebook story works and may not be as meaningful for the children.

A study was done in the United Kingdom on two groups of children to determine how "talking book software" affected phonological awareness skills (Wood, 2005). A total of 80 students from the same school that participated in this study. The groups were comprised of two age levels. The first group contained 40 five year olds and the second group was made up of 40 six year olds. Each age group was then split in half with the various conditions, talking book or traditional book with teacher support. The students in the traditional book group had six sessions that lasted no more than 15 minutes each with the research assistant with at least three days in between sessions. During the sessions, the child was asked to read a book, and if they needed help the adult would help them. The children were pre-and post-tested using the Phonological Assessment Battery test, which tested rhyme awareness, alliteration, rapid picture naming and fluency. They also used an assessment that looked at error analysis of the child's reading (Wood, 2005). After the comparison group was assessed the research assistant then worked with the intervention group. The intervention group of children were shown how to use the software and 
used the program independently during their six sessions. The post-test was given about a week after the interventions were completed. The results from this study suggest that the intervention and comparison group did not have significant differences in overall phonological awareness skill acquisition, but there was evidence that the software helped make gains with rhyme detection and that the children had some changes in their reading strategies between the pre-and post-tests.

A study done by Richter and Courage examined preschool aged students recall of information and engagement in the story which is read to them from a paper book and read to from an ebook (2017). This study assessed 79 preschool (three to five year old) aged children from middle SES backgrounds. The children were read aloud two different stories in different formats, one was an ebook and the other a paper copy. The format of the story and title selection were counterbalanced between the children. The books were read at the child's pace as they determined when to turn the page and how long to stay on each page. Following the reading of both books, the children were assessed using multiple assessments. The results from this study showed that generally children were more engaged during the ebook than during the paper copy books. The study mentioned that the child's level of executive function was more of a predictor for their engagement and attention to the books, than was their age. The study also found that the children's story recall was the same between the two formats of books being read.

\section{Ebooks Are Not Good for Emergent Literacy Skills}

There is some research that has results showing that using electronic books with young children does not help with the child's reading comprehension skills. In this next section, I will review these articles and their findings. 
A two-part study conducted by Parish-Morris, Mahajan, Hirsh-Pasek, Golinkoff, and Collins (2013) examined the effects of ebook reading on child's literacy skills, compared to traditional books. Parish-Morris et al. (2013) completed the first study which looked at parentchild language during shared book reading. The first study found that story related discussion was limited when using the electronic books, which lead the researchers to wonder what that meant for the child's reading comprehension of the stories. The second study examined reading comprehension more closely. For the second study 40 three-year-old children and 33 five-yearolds and their parents were used. The majority of parent participants were mothers. The parent child pairs were randomly assigned to either read a traditional version of a child's book or an electronic form of a book. After the reading the parent left the room to do a survey and an examiner worked with the child. The child was assessed on character identification, identification of key events in the story, content of story (such as if in one of the stories the characters drove or walked where they were going), and story sequence. The researchers identified five year olds maxed out on all of the tests, and had no differences between the electronic and traditional form of the book, therefore the only results that were analyzed were the ones from the three year olds. The results from the three year old study showed that when the three year olds read with traditional books, they were able to answer more content questions correctly and were also able to more closely tell the stories sequence. They also found that although the students who were reading the electronic books could identify characters and events of the story at the same rate as their peers who read with traditional books, the ebook readers had a harder time with the more in-depth questions, such as story structure and details of the story (Parish-Morris et al., 2013).

A similar study was done by Krcmar and Cingel (2014) to evaluate young children's 
reading comprehension when they are read to by parents using both ebooks and traditional books. In this study 70 parent child groups participated, and the median age of the participants was four and a half years old and gender was equally distributed. Almost all of the parent participants were mothers. For this study, the parent read their child two different books. One in an electronic form and one in a traditional paper copy. Both books were in digital and paper copies and the parents rotated which book was read first, and ensuring to read both books. This study was not conducted in the home with the parents, but instead was conducted with the child and parent together in a testing room. Children were assessed on comprehension skills by answering multiple choice questions with two options. These questions were directly related to the storyline of the books being read. When the child was asked each question the two answer options were verbally provided and a picture of the response was shown, so the child was allowed to just point to their answer if not verbally expressed. The children could score zero to seven points for each book read. The results showed that the average score for the traditional book were slightly higher than the ebook, but the difference in scores were not found to be statistically significant on their own. The study did find that the children whose parents reported higher technology usage time scored higher on the traditional book while the children whose parents reported lower technology usage time scored higher with the ebook. This finding was not statistically significant.

Segal-Drori, Korat, Shamir, and Klein (2010) did a study that focused on the differences in children's emergent reading skills as measured by the child's concepts about print, phonological awareness and word reading skills, in four different settings. The four conditions included, independently reading an ebook, reading the ebook with adult instruction, reading a traditional paper copy book with adult instruction, and the control group, which received the 
regular kindergarten class with no intervention added. The participants were 128 kindergarten children ranging in age from five to six years of age. This study was done in Israel in low SES neighborhoods. Each of the participants were randomly assigned one of the above-mentioned groups. The intervention included two students at a time, working as a pair, for four sessions. For the groups that received adult instruction, the instruction was done before and after the reading of the books. The instruction focused on emergent reading skills, such as print concepts, and drew attention to ten keywords in the story. The results from this study showed that the children who were in the group that experienced the ebook with adult instruction, outperformed the other groups when it came to word reading and concepts of print. The participants had greater progress with phonological awareness, compared to the students who just used the ebook with no adult instruction and control groups. The researchers also found that the children who were in the group that was read the print book and had adult instruction, made progress on their phonological awareness, but not on their concepts of print. The children in the ebook and instruction were able to make gains in all three areas. This study seemed to suggest that ebooks are helpful, however added adult instruction is needed. The use of ebooks alone did not promote the early learning skills. 


\section{Chapter III}

\section{Conclusions and Recommendations}

With this paper, I have reviewed multiple studies that discussed how young children are using technology to acquire and develop emergent literacy skills. I have discussed how children are exposed to and use technology at home as well as teachers' beliefs on the use of technology in the classrooms. I also found research showing multiple viewpoints on whether or not ebooks are superior to reading traditional books with students in their journey to learn new literacy skills. In this final chapter, I will put together my insights from this research along with giving some recommendations, ideas on future projects, and how this review may influence educational policy and or teachers' practices.

\section{Insights Synthesized, Recommendations}

This review began by evaluating children's exposure to technology in the home. These various studies were with children starting at the age of two years old all the way to third grade. The results from these studies suggest that children are getting a lot of exposure to technology even when not using the actual device. While getting this exposure they are observing how and when their family members use the devices and while doing so learning cultural norms about the use of technology. These findings suggest children are learning from a very young age and parents should be mindful of their use of technology around even their very young children (Plowmanet al., 2012; Espinosa et al., 2006; Lauricella et al., 2014; Neumann, 2016).

Information regarding different formats of games children played at home was also reviewed. There were some findings that showed a positive association between children using literacy apps and tablet writing and typing, however, there was no positive association found 
between gaming apps and writing (Neumann, 2016). Espinosa et al. explained that watching TV, even shows that are thought to be educational like Sesame Street did not have positive literacy outcomes for children (2006). Playing computer based literacy games had a small positive effect in kindergarten, but by third grade started to have a negative impact on their literacy outcomes. These findings suggest that although sometimes adults' intentions are good, using technology as a primary tool for instruction is not always the best idea. Teachers and parents need to make sure that they are very intentional while letting children use technology and make sure that they monitor the use and make sure that the students are getting to intended benefits from using the technology. If the outcomes are not changing and the children are not making gains, it might mean that a different form of instruction is needed or the app that they are using is not effective for that child.

Lastly, I examined an article that discussed parents' use of ebooks with their children at home. The study looked at how parents interacted with their child while using an ebook and traditional books. The study found that parents defined words more while reading traditional books, but were more engaged during ebooks. This study ultimately found that both computer based ebooks and traditional books are beneficial to use with children. The findings suggested that any way you can read to a child would be beneficial to the child. Parents and teachers need to remember this when deciding priorities when it comes to reading at home and school. When parents are busy or running errands, it is important to remember that even though the family is not close to a paper copy book, they could use their phone to find a book to read with their child.

When reviewing articles focused on teacher's use of technology in the classroom, findings showed that it is important for teachers to have support while implementing any new 
technology. Teachers need ongoing support to ensure they are using the technology to its fullest potential. These findings suggest that when administrators, teachers and/or policy makers are going to mandate new technology use, they need to consider how much initial and ongoing support will be provided. When recommending new technology, it needs to be a priority that ongoing learning and support for the teachers is budgeted (Blackwell et al., 2014). The second biggest finding from these articles was teachers' beliefs regarding technology use has a huge impact on implementation in the classroom. If a teacher does not see value in using technology with their students, they are less likely to use technology (Ihmeideh, 2010; Blackwell, 2013). This finding suggests that teachers need to be informed on the benefits of technology. If a teacher is more informed and supported with the use of the technology, it will be easier for educators to be more excited to use it, leading to more use of technology in the classroom (Blackwell et al., 2014).

To answer the third question, I looked at ebooks as an effective way to teach young children emergent literacy skills. My findings were mixed regarding literacy skill instruction. I was able to find multiple articles showing ebook usage was more effective than traditional books (Korat, 2010; Ihmeideh, 2014; Rvachew et al., in press; Shamire \& Korat, 2007) or equally as effective as traditional books (Willoughby et al., 2015; Broemmel et al., 2015; De Jong \& Bus, 2004; Wood, 2004; Ritchte \& Courage, 2017). However, Parish-Morris et al (2013), Krcmar \& Cingel (2014), and Segal-Drori et al. (2010) conducted research that indicated ebook usage was not as effective. These findings suggest that more research should be conducted to find a more definitive answer to this question. There needs to be longer studies done to show the long-term effects with young children. For example, how using technology as a young child effects academic outcomes as the child gets to middle or high school. Are there any positive or negative 
associations with children being exposed to technology earlier in life? There also needs to be more research done with younger children, specifically nonreaders. Much of the research was done on children who were already or just beginning to read. Being a preschool teacher who is teaching students who cannot read, it would be interesting to find more research linking the effects of technology with this aged child. Information on whether or not technology helps nonreaders learn how to read or learn skills more quickly is needed.

\section{Future Projects/ Research}

While searching for research for this paper, I found many studies done overseas. Doing research in the United States to see if the same results are true with English speaking students could expand upon this research base. Knowing that school systems around the world have varying structures and values, it would be beneficial to have more research from the United States to use when thinking about technology use with my students.

The research that I found frequently worked with students five years and older. Future research could be done to examine the use of technology with younger students, even as young as two years old. This research could be done with specific apps or specific kinds of apps such as literacy or academic focused apps verses gaming apps (Angry Birds, LEGOs, etc). I also see the need for future research in more longitudinal studies showing the risks and benefits of children who use technology from a young age and their academic advancement later in life.

\section{Teacher Practices}

When thinking about what my research has told me about teachers' practices with technology use in the classroom, one of the biggest takeaways was that teachers need to make 
sure that they have support when implementing and using technology with young children.

Teachers need to make sure they understand how to use the technology themselves and if they do not, then they need to make sure they are getting the training needed to be able to implement it fully. As technology will always be changing, teachers also need to ensure that they are always keeping up with how to best use the newest technology to help their students. 


\section{References}

Blackwell, C. (2013). Teacher practices with mobile technology: Integrating tablet computers into the early childhood classroom. Journal of Education Research, 7(4), 1-25.

Blackwell, C. K., Lauricella, A. R., \& Wartella, E. (2014). Factors influencing digital technology use in early childhood education. Computers \& Education, 77, 82-90.

Broemmel, A. D., Moran, M. J., \& Wooten, D. A. (2015). The impact of animated books on the vocabulary and language development of preschool-aged children in two school settings. Early Childhood Research \& Practice, 17(1), n1.

Espinosa, L. M., Laffey, J. M., Whittaker, T., \& Sheng. Y. (2006). Technology in the home and the achievement of young children: Findings from the early childhood longitudinal study. Early Education and Development, 17(3), 421-441.

De Jong, M. T., \& Bus, A. G. (2004). The efficacy of electronic books in fostering kindergarten children's emergent story understanding. Reading Research Quarterly, 39(4). 378-393.

Ihmeideh, F. (2010). The role of computer technology in teaching reading and writing: Preschool teachers' beliefs and practices. Journal of Research in Childhood Education, 24(1), 60. Retrieved from https://login.proxy.lib.uni.edu/login?url=http://go.galegroup.com.proxy.lib.uni.edu/ps/i.d $0 ? p=A O N E \& s w=w \& u=u n i$ rodit $\& v=2.1 \& i t=r \& i d=G A L E \% 7 C A 223823304 \& a s i d=c .5 b 4$ 64df861.35d6dc83616dbet34d9e4

Ihmeideh, F. M. (2014). The effect of electronic books on enhancing emergent literacy skills of pre-school children. Computers \& Education, 79, 40-48. 
Korat. O. (2010). Reading electronic books as a support for vocabulary, story comprehension and word reading in kindergarten and first grade. Computers \& Education. 55(1), 24-31.

Krcmar, M., \& Cingel, D. P. (2014). Parent-child joint reading in traditional and electronic formats. Media Psychology, 17(3), 262-281.

Lauricella, A. R., Barr, R., \& Calvert, S. L. (2014). Parent-child interactions during traditional and computer storybook reading for children's comprehension: implications for electronic storybook design. International Journal of Child-Computer Interaction, 2(1). $17-25$.

Radich, J. (2013). Technology and interactive media as tools in early childhood programs serving children from birth through age 8. Every Child, 19(4), 18.

Neumann, M. M. (2016). Young children's use of touch screen tablets for writing and reading at home: Relationships with emergent literacy. Computers \& Education, 97, 61-68.

Parish-Morris, J., Mahajan, N., Hirsh-Pasek, K., Golinkoff, R. M., \& Collins, M. F. (2013). Once upon a time: parent-child dialogue and storybook reading in the electronic era. Mind, Brain, and Education, 7(3), 200-211.

Plowman, L., Stevenson, O., Stephen, C., \& McPake, J. (2012). Preschool children's learning with technology at home. Computers \& Education, 59(1), 30-37.

Richter, A., \& Courage, M. L. (2017). Comparing electronic and paper storybooks for preschoolers: Attention, engagement, and recall. Journal of Applied Developmental Psychology, 48, 92-102.

Rvachew, S., Rees, K., Carolan, E., \& Nadig, A. (in press). Improving emergent literacy with 
school-based shared reading: Paper versus ebooks. International Journal of ChildComputer Interaction. Retrieved from http://www.sciencedirect.com/science/article/pii/S2212868916300472

Segal-Drori, O., Korat, O., Shamir, A., \& Klein, P. S. (2010). Reading electronic and printed books with and without adult instruction: Effects on emergent reading. Reading and Writing, 23(8), 913-930.

Shamir, A., \& Korat, O. (2007). Developing an educational e-book for fostering kindergarten children's emergent literacy. Computers in the Schools, 24(1-2), 125-143.

Wild, M. (2009). Using computer-aided instruction to support the systematic practice of phonological skills in beginning readers. Journal of Research in Reading, 32(4), 413-432.

Willoughby, D., Evans, M. A., \& Nowak, S. (2015). Do ABC eBooks boost engagement and learning in preschoolers? An experimental study comparing eBooks with paper $\mathrm{ABC}$ and storybook controls. Computers \& Education, 82, 107-117.

Wood, C. (2005). Beginning readers' use of 'talking books' software can affect their reading strategies. Journal of Research in Reading, 28(2), 170-182. 